\title{
Accounting
}

\section{Accounting improving the costs and business process management in transportation to a third party}

\author{
Heyder G Wannes Alkarawy ${ }^{a^{*}}$ and Ezdehar J. Mohammed AL-Kuwair ${ }^{a}$
}

${ }^{a}$ Department of Banking and Finance, College of Administration and Economics, University of Babylon, Babylon 51002, Iraq

\begin{tabular}{l}
\hline C H R O N I C L E \\
\hline Article history: \\
Received: October 27, 2020 \\
Received in revised format: \\
November 262020 \\
Accepted: December 9, 2020 \\
Available online: \\
December 9, 2020 \\
\hline Keywords: \\
External source \\
Business organization \\
Commercial operations
\end{tabular}

\section{Introduction}

Since the use of an external source is a comprehensive strategic decision, its adoption causes major changes to the structure and results of business, and therefore requires substantial analytical training, review the sources of research and recent publications. Some issues related to the regulation of the mechanism of external business operations are reflected in studies of foreign and domestic researchers (Ala'a, 2016; Christian, Diego, \& Lucas, 2017; Bailal, 2018; Ruiz-Medrano, 2019) and others. There is no doubt that the basis of information and practical knowledge can be used by companies in their activities, which is the purpose of the strategic decision to make the company more competitive and maneuverable through its economic activities, and that the concept of external source takes advantage of this approach by successfully transferring the activities of companies to outsourcing (Stojanov, 2017). However, the problems of developing an effective mechanism to regulate the outsourcing in the Republic of Iraq for auxiliary business operations to industrial enterprises in an optimal regulation of economic processes and the formation of an effective system to support it require more systematic research and in-depth learning. Modern management technologies occupy a special place in the process of adapting institutions to instability in external conditions, in particular, associated with the widespread use of outsourcing (Nesma, 2018). Despite the rapid development of the business process outsourcing, it is still not widespread in Iraq. This is due to the low degree of corporate movement, and companies fear losing control or exclusive information, and assigning trade secrets to third parties (Al-Jajjawi, \& Al-Masoudi, 2004). In other words, there is a lot of instability in demand and competition for manufacturing costs, through operations of the business process outsourcing. Therefore,

* Corresponding author. Tel: +9647817391489

E-mail address: hw_22298@yahoo.com (H. G. W. Alkarawy)

. 
one of the main objectives within the business world is the management decisions in organizing and managing a transfer mechanism to the third party. At the same time, the use of outsourcing in the practice of companies will increase the efficiency of the enterprise, which will be reflected in the short term in the rational management of costs and is designed to make the company in a state of optimal compliance with market requirements (Jumana, 2014; Imad, \& Ala'a, 2016; Abdul, 2019). This reinforces the idea of the institutions adapting to development in order to achieve competitiveness in the market. Christian, Diego, \& Lucas, (2017), examine the attempts to outsource, is the contracting companies have more time to focus on their main activities, and can also count on the partial transfer of responsibilities to the contracted company. This work is justified by, nowadays, with the market increasingly competitive, the calculation of costs in needs attention, as it influences the price and, consequently, the performance of organizations in the market. In this context, to benefit from the advantages of industrial outsourcing agreements between small and large companies to achieve the following objectives (Ruiz-Medrano, 2019):

- Increase production and employment levels.

- Improve productivity and international competitiveness.

- Improve manufacturing processes and products.

These goals require the adoption of changes in the structure and the results of the business, which supports a mechanism for the formation of a system for managing business processes for companies. Alnoor and Leslie (2014) examined the impact of the use outsourcing that requires building a clear and logical structure for managing business operations and forming an effective regulatory and economic mechanism for managing essential and auxiliary business operations, outsourcing into production, IT outsourcing and business process outsourcing (provide sustainable competitive advantages), and on the other hand, the flexibility of the enterprise and the ability to quickly adapt to environmental requirements (Alkarawy, 2018). It supports the view that compliance with the requirements of flexibility in maneuver through the transformation of some activities to outsourcing to achieve the competitiveness of the company to supports the strategic management decision to build a structure to manage commercial operations when turning to outsourcing. Global experience in implementing outsourcing shows that the main advantage of this form of business organization is to save costs on implementation and improve the quality of "non-essential" types of activities, which is especially important in difficult social and economic conditions as well as in economic crises. However, the conclusion about the effectiveness of outsourcing is not clear, and therefore, there are many methodological and applied problems in its implementation in the enterprise management system. The formation of a system to provide a mechanism to regulate the use of an external source for auxiliary business operations for enterprises in modern conditions for the work of industrial enterprises is important. This paper is as follows. The paper outlines the distinctions between subsystems for the purpose of providing a mechanism to regulate transportation (outsourcing) operations, assess the impact of outsourcing on the performance of industrial enterprises in the Republic of Iraq, and provide a quantitative standard for the measuring outsourcing. Then a ten-point scale is provided in favor of measuring transfer to outsourcing operations in three forms.

\section{Related literature}

The regulatory and economic mechanism for interacting in a complex system, which is an industrial organization (Katerina, 2017), including an agreed system of goals, strategies, standards, and conditions (in particular, resources), based on the following,

- Create a database, links and chains in the system.

- Methodology of financial, media and technological interaction of the elements among themselves and with the external environment.

- Leverage methods, plans, prices, standards, etc.

- Financial and operational management methods; administrative and financial restrictions on the activities of commercial entities within the system and in the external environment (Adesubomi, 2015; Shadrack, 2017). The current economy requires companies to be in tune with changes in the market, which is complex and globalized, in other words, there is a lot of instability in demand and competition for manufacturing costs (Diego, Cleiton, \& Carlos, 2020). The organizational and economic mechanism for organizing the outsourcing of auxiliary business operations to enterprises should be seen as a set of regulatory and economic tools (each with its own forms of administrative impact), which affect the economic and organizational parameters of the project management system, and contribute to shaping and enhancing organizational and economic potential, access on the competitive advantages and effectiveness of the project as a whole (Abdullah, \& Aykut, 2014; Svetlana, \& Elina, 2015). The regulatory and economic mechanism for organizing the outsourcing of auxiliary business operations to enterprises is identified in the context of the theoretical and general level through a comprehensive process that requires an effective support system. Based on an analysis of professional economic literature, can be distinguished the following subsystems to provide a mechanism for organizing the outsourcing of auxiliary business processes to industrial enterprises: Financial, informational, technical and organizational. The structure of the mechanism for organizing the outsourcing of business processes of enterprises is presented in Fig. 1 and provides financial support for the formation and use of financial resources to meet the needs of the organization, which is regulated by the relevant regulatory laws that define how it is mobilized, distributed and used at all levels of economic management (Galina, 2019). Information support is a set of tools and methods for documenting and organizing data storage, coding, and information retrieval 
about the status and behavior of systems and subsystems of the outsourcing generation process for business auxiliary businesses (Sung, Gopesh, Eric, \& Joseph, 2019; Havakhor, \& Sabherwal, 2019).

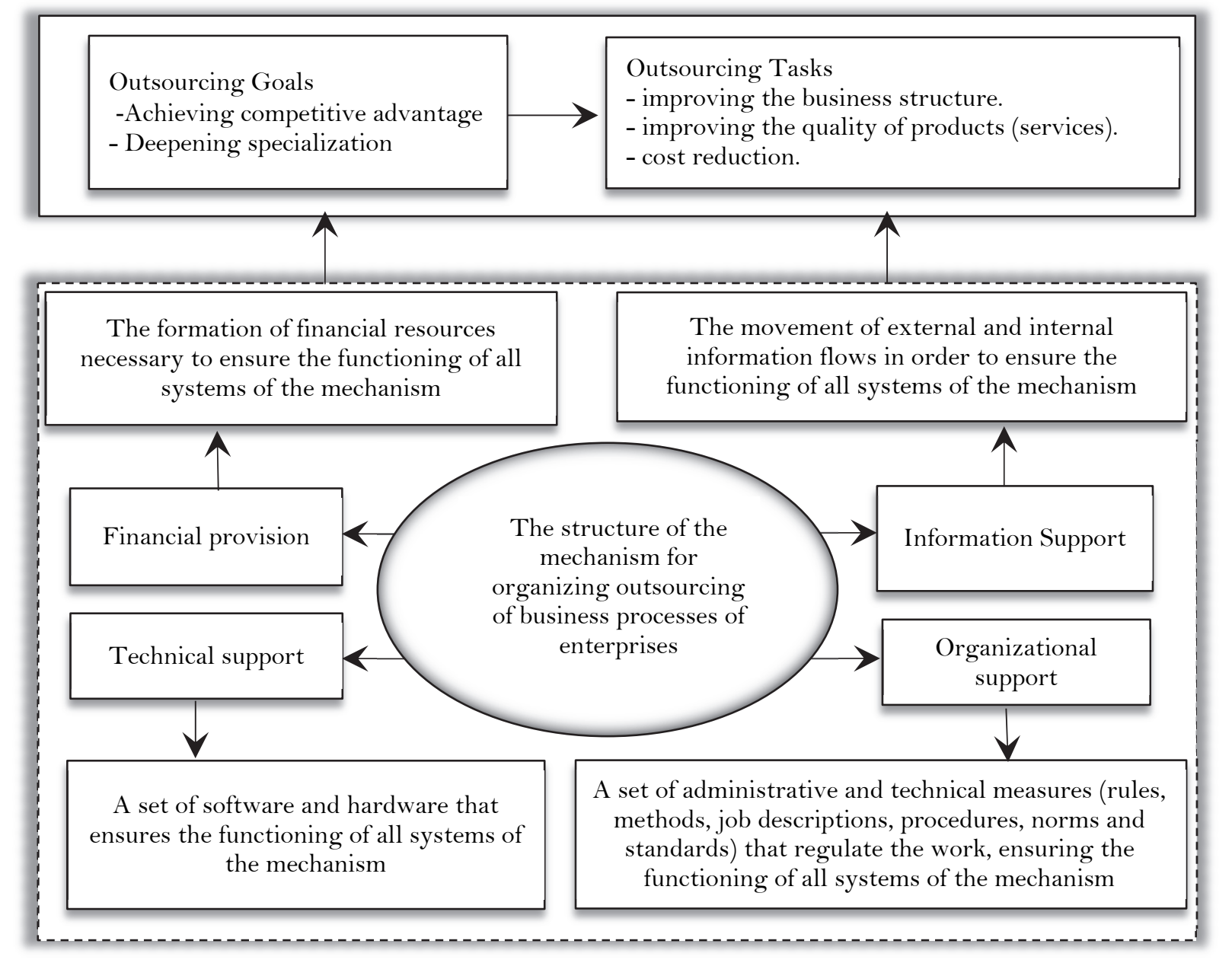

Fig. 1. Shows the structure of the outsourcing mechanism for corporate business operation (Alkarawy, 2018)

Generally, the information support system consists of three main blocks: structural information, planning information, and an operational information unit. The introduction of an effective information system should coordinate the activities of all of its departments and employees on the basis of synchronization of production and management processes. The mechanism's advantage is the presence of a feedback channel. After receiving feedback from the regulated system, this system produces the audit information. The latter, in turn, becomes input information to implement the regulatory function or direct approval of an administrative decision. Organizational support is a complex set of administrative and technical measures (rules, methodologies, job descriptions, procedures, rules, and standards) that govern the work of those who provide jobs all systems of the mechanism of formation of outsourcing of auxiliary business operations of enterprises (Ioan, \& Vasile, 2010; Jordan, 2017). Technical support is a set of software tools for gathering, processing, analyzing and distributing information, as well as devices that ensure the functioning of all automated systems. Every industry in the industry is in very competitive conditions, requiring research on options to reduce costs. Due to the large number of stages of production in the industrial enterprises of industry, a large number of workers are concentrated, each of whom is assigned certain jobs. The workload index is closely related to the ability of employees to perform other business operations, because versatility allows you to engage an employee in different operations, and this reduces the possibility of outsourcing the organization. In general, outsourcing is usually used as a component to reduce cost and focus on key tasks, and therefore, the high cost of the process requires finding ways to reduce costs, but more often it is used to improve the quality and speed of the process implementation, which in turn speeds up the operating cycle, which is One of the main indicators of success. Therefore, a longer duration of the operating cycle can facilitate the transition to outsourcing and vice versa. It is advisable to use marginal income as a basis for the percentage of outsourcing, as revenue is the main indicator of industrial enterprises. The proportion of variable costs is large in the cost of commercial operations of industrial enterprises (Nataliya, Alkarawy, \& Vladimir, 2016). Calculating the outsourcing coefficient when executing commercial operations in industrial establishments determines the specific weight of marginal income at full cost, that is, the outsourcing coefficient shows the number 
of monetary units of marginal income generated by each monetary unit of expenditures (Furusawa, Ito, Inui, \& Heiwai, 2015; José, Alberto, \& Ana, 2016). This indicator should approach the maximum, which means that its increase is considered a positive trend.

\section{Methodology}

Given its characteristics, the research corresponds to a qualitative-quantitative type, of a descriptive nature, in which the application of determine the decision on the use of outsourcing, defined a comprehensive quantitative evaluation criterion for the effectiveness of outsourcing and quantitative techniques such as the application of surveys to operations in Harrington scale, which favored the measurement - the ratio of the business process cost to average cost. Primary sources such as fairly complete method of reforming the company on the basis of outsourcing, whose purpose was to explore, to understand processes and identify the problems of organizing outsourcing in industrial companies (Anokhin, 2010). This method allowed to count events, conditions or situations in detail, being able to use figures, qualities or the combination of them in the choice of business process for outsourcing; determination of criteria for process evaluation and identification of possible implementation scenarios; collection of information about potential partners according to selected criteria; scenario assessment; processing of the selected scenario. In addition, one company developed a methodology for identifying "redundant businesses" for which it is necessary to make a decision on sale, outsourcing, destruction, etc. This technique includes (Anokhin, 2010).

Stage 1. Evaluation of each activity of the company according to two criteria: compliance with the strategic goal of the business and the efficiency of the unit (return on assets).

Stage 2. Assignment of each of the units to one of four groups: highly effective with a high degree of compliance with the strategy; highly effective with a low degree of compliance with the strategy; low-efficiency with a high degree of strategy compliance; ineffective with a low degree of compliance strategy, which in this case refers to transformations accordingly:

-sale of non-core assets with low efficiency;

-allocation of non-core assets with high (even in the future) efficiency to a separate enterprise.

According to Jumana, (2014), the well-known "outsourcing matrix" is used, which consists of 9 fields and provides for the separation of competencies, functions, technologies in its main nine fields and decision-making on the feasibility of outsourcing. With the development of this article, it is intended to get an idea of the numerical quality indicators for the selected criteria, to justify the feasibility of outsourcing certain manufacturing processes.

\section{Results}

We provide an evaluation of the impact of the introduction of outsourcing on cost-efficiency and increasing the efficiency of the organization, followed by the determination of the decision regarding the use of outsourcing that takes into account the main factors affecting the operating profit of the organization when carrying out business operations (marginal income, total cost, and other operating income). Then show the feasibility of outsourcing in industrial enterprises and calculate their effectiveness, followed by an interpretation of the average values obtained for estimates of relative parameters on a ten-point system.

\section{Provide a model for assessing the impact of outsourcing and a comprehensive evaluation standard system for the effectiveness of outsourcing on enterprise performance}

To monitor quotes for potential outside contractors, it is necessary to calculate the outsourcing factor when submitting the latter. At the same time, the numerator for the formula for determining the outsourcing factor includes the amount of other operating income that an institution can obtain from a third party. The introduction of outsourcing schemes leads to an increase in the outsourcing factor (i.e. the percentage of marginal income in total cost increases), and an increase in operating profit and core business profitability (Bailal, 2018). There are cases in which the use of outsourcing leads to a decrease in its percentage, due to the large costs and requires the introduction of measures aimed at reducing fixed costs, finding a cheaper outsourcing quote or obtaining other operating income by providing services. An evaluation of the impact of outsourcing on improving cost and improving the efficiency of business outsourcing business has a positive impact on the organization's key financial and economic indicators: there is a decrease in total cost, an increase in marginal income, operating profit and profitability of operational activities and according to the explicit relationship between the established categories and the resulting representations we compiled it based on these relationships and presented it in the Fig. 2. To determine the decision on the use of outsourcing, we have defined a comprehensive quantitative evaluation criterion for the effectiveness of outsourcing - the outsourcing factor $\left(F_{\text {out }}\right)$, which takes into account the main factors affecting the organization's operating profit when carrying out business operations (marginal income, total cost, and revenue other operating). We show the feasibility of outsourcing in industrial enterprises and calculate its effectiveness in accordance with business processes at the stages of industrial enterprises using expert assessments. It is suggested that the average values obtained for the estimates of relative parameters be interpreted on the Harrington scale translated into a ten-point system. The viability index of the need to outsource the business process can take values (from 0 to 10 , while the low level of the index from 0 to 3.7 points) indicates the need to move the business process to full outsourcing, and a high level (from 6.4 points) And above) - on the appropriateness of carrying out commercial operations on their own. Accordingly, the average overall index level (from 3.7 to 6.4 points) indicates that the business process can be converted to partial outsourcing. At the same time, it is necessary to distinguish between business operations with an average level of the overall index that can be given for 
both full and partial outsourcing (from 3.7 to 4.6 points): those that can be converted to partial outsourcing (from 4 , from 6 to 5.5 points), And those that can be converted to partial outsourcing or done alone (from 5.5 to 6.4 points). Taking into account the above, to make a decision to move the business process to outsourcing only on the basis of attribute criteria is impractical, and therefore, in proving such a decision, of translating the coefficients presented in Table 1 are obtained using a quantitative standard - the ratio of the business process cost to average cost. The procedure for translating and interpreting transactions for the ratio of business process costs to average value of expenditures in points is presented in Table 1.

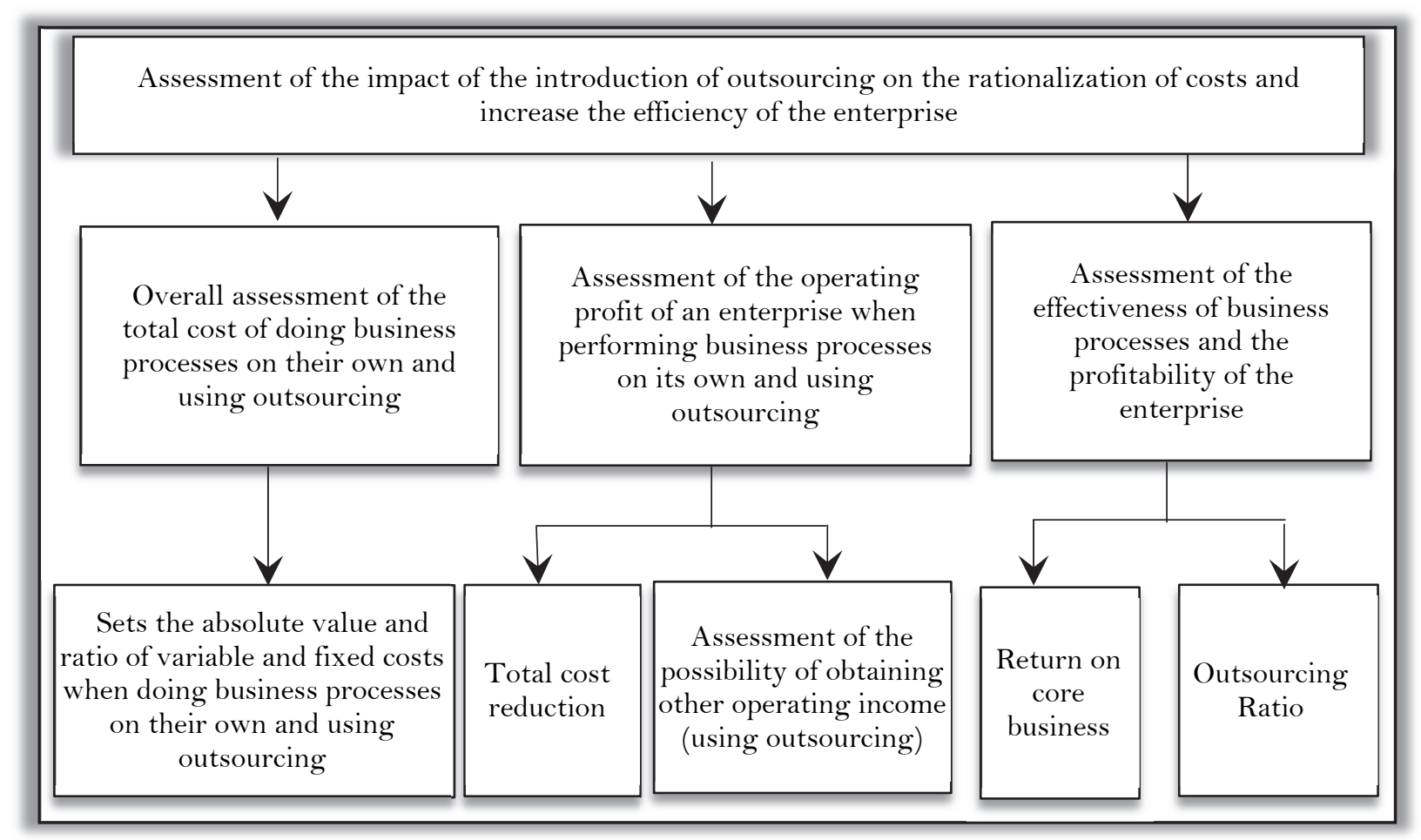

Fig. 2. Assessing the impact of outsourcing on the performance of an industrial enterprise

Table 1

The scale for translating the coefficients of the ratio of costs of the business process to the average cost in points

\begin{tabular}{lccc}
\hline \multicolumn{1}{c}{ Rating } & Base scale & & \multicolumn{2}{c}{ Modification scale } \\
\hline Very high & Numerical value, units & Rating & Numerical value, points \\
High & $8,0-10$ & High & $6,4-10$ \\
Average & $6,4-8,0$ & Average & $3,7-6,4$ \\
Low & $3,7-6,4$ & Low & $0,0-3,7$ \\
Very low & $2,0-3,7$ & & \\
\hline Source & $0,0-2,0$ & &
\end{tabular}

Source: The authors' elaboration

The possibilities of using various methods for assessing the effectiveness of outsourcing are based on the basic principles of the analysis of economic efficiency. In order to get an idea of the numerical quality indicators for the selected criteria, a model was created using expert estimates. Experts were asked to answer a number of questions. Answers to these questions were pointers to each set of factors that influence the decision to outsource. Calculating the feasibility indicator suggests deciding on moving the business process to outsourcing as follows:

$$
F_{\text {out }}=\frac{Q_{1}+Q_{2}}{N_{q \& q}}
$$

where $Q_{1}$ is a qualitative indicator of the rationale for outsourcing in a business process.

$Q_{2}$ - a quantitative indicator for the rationale for moving the business process to outsourcing.

$N_{q \& q}$ is the number of relative and quantitative criteria taken In mind when deciding on the rationale for converting the business process to outsourcing. A qualitative indicator to justify moving a business process to outsourcing is calculated according to formula

$$
Q_{1}=D_{s}+D_{g}
$$

where $D_{s}, D_{g}$ are degrees of the strategic importance of the business process and the quality of its implementation. A quantitative index is calculated to justify moving the business process to outsourcing according to formula 
$Q_{2}=10-E_{R}$

where $E_{R}$ represents an estimate of the cost-to-average ratio. This allocation of points allows for more flexible decisions, and also gives management personnel room for maneuver. Based on the data collected, the perceptions of the expert evaluation data obtained according to the "business process significance", "business process quality" and "cost ratio" criteria are included. We have compiled a list of potential experts in the amount of (40) people, of which (10) people with a high level of competence were subsequently selected, because the staff of the expert group from the total number of applicants is composed of the most competent specialists who can show the maximum ability to predict the future and adequately display trends and patterns of development of the investigated process (phenomenon, object) in the Table (2), and based on them, an rationale index is calculated for converting the business process to outsourcing in the industrial establishment - State Company For Implementation (SCI) Iraqi.

Table 2

The results of evaluations by experts of business processes of an industrial enterprise - State Company for Implementation (SCI)

\begin{tabular}{|c|c|c|c|c|}
\hline Business process & $\begin{array}{c}\text { The importance of the } \\
\text { business process }\end{array}$ & $\begin{array}{c}\text { Quality of business } \\
\text { operations }\end{array}$ & Cost ratio & Comprehensive indicator \\
\hline Administrative support & 4 & 6 & 4 & 5.3 \\
\hline Supply of raw materials & 6.8 & 6.2 & 6.8 & 5.4 \\
\hline Provision of equipment & 6.3 & 6.4 & 7 & 5.2 \\
\hline Installation of systems & 3.4 & 9.6 & 3.8 & 6.4 \\
\hline Technological support & 1.5 & 1.7 & 4 & 3 \\
\hline Logistics & 6 & 6.1 & 5.5 & 5.5 \\
\hline Service maintenance & 1.6 & 1.5 & 2.5 & 3.5 \\
\hline Production planning & 6.4 & 6.2 & 3.6 & 6.4 \\
\hline Organization of production. & 6 & 5.7 & 4.5 & 5.7 \\
\hline Strategic management & 8.4 & 6.2 & 6.1 & 6.2 \\
\hline Financial management & 8.8 & 6.5 & 5.2 & 6.7 \\
\hline Marketing management & 6.5 & 6 & 3.9 & 6.2 \\
\hline Quality control & 8.4 & 6.6 & 4.8 & 6.7 \\
\hline Personnel Management & 7.5 & 7 & 5 & 6.5 \\
\hline
\end{tabular}

According to the results of the study in the institution - State Company for Implementation (SCI) demonstrated the need to transfer it to full outsourcing (from 0 to 3.7 points) two of the business process.

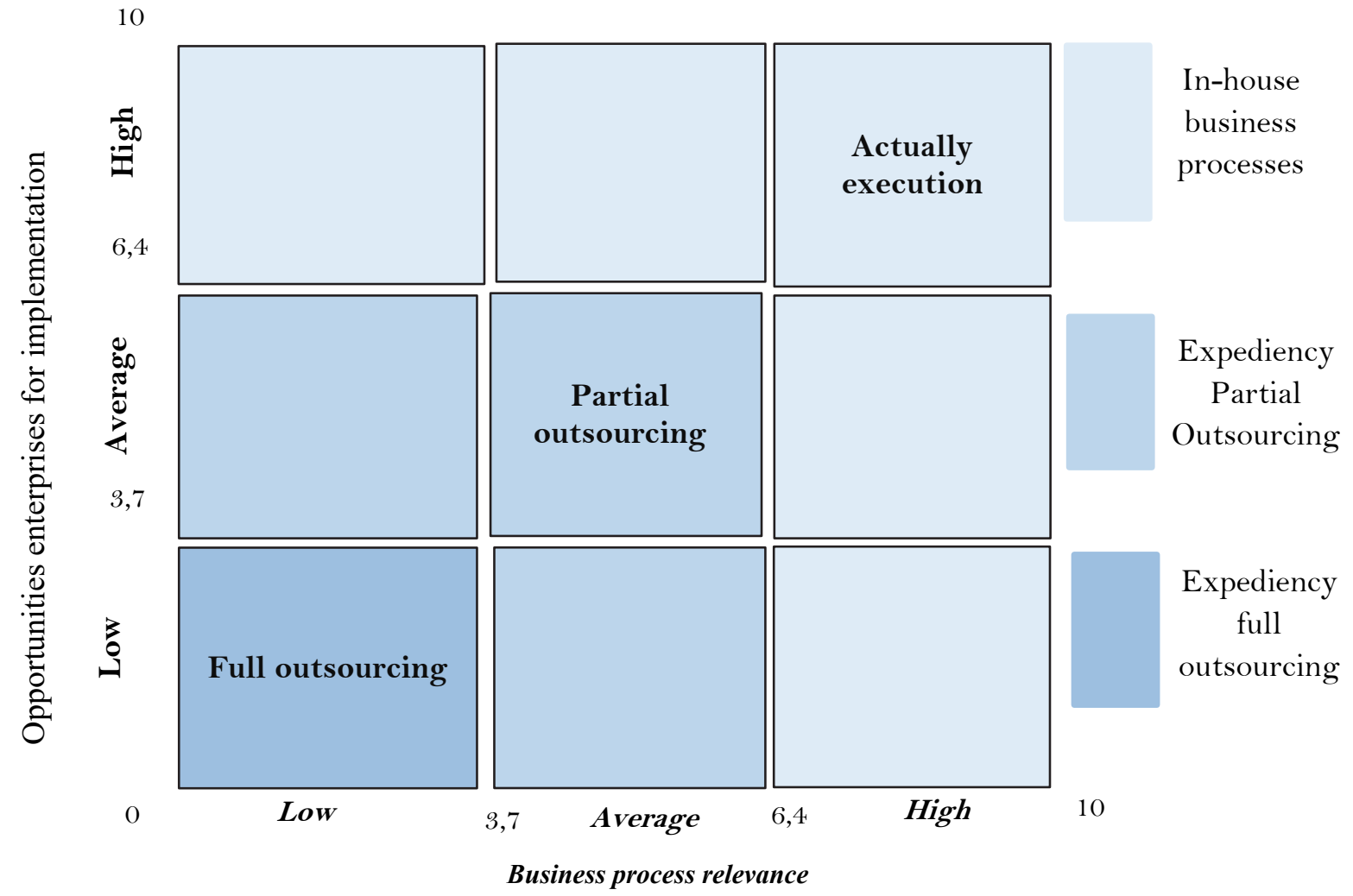

Fig. 3. I he matrix of the teasibility of 1mplementing outsourcing in the enterprise 
The decision on partial transfer, it showed that seven of the business processes are partially transferred to outsourcing is unambiguous. In addition, taking into account the criteria of the importance of business processes, the quality of their implementation and the share in the costs of the institution, five more business process can be outsourced or performed on their own. However, the institution became more agile internally, maintaining an expressive performance brought improvements to the institution by making a decision to transfer the useless business process internally to outsourcing. In this way the strategic objectives of the institution were achieved by minimizing the useless business process and focusing on their basic operations. Accordingly, this process of point's distribution will help the departments to choose and maneuver according to the processes that pertain to each institution. It is suggested that a clear definition of the type of outsourcing or other project strategy be made on the basis of building the feasibility matrix of outsourcing the organization's activities (see Fig. 3). The proposed evaluation matrix of the appropriateness of using outsourcing at the enterprise will allow not only to comprehensively evaluate the business process and the possibilities for its implementation at the enterprise, but also make an informed decision regarding the fate of the chosen business process. When evaluating business processes, it is possible to make a decision - to concentrate our own resources on its improvement or to attract an external organization for the full or partial implementation of business processes. This will increase the efficiency of business processes, labor productivity, as well as create the prerequisites for the modernization and growth of the enterprise, increase competitiveness in the market, which will lead to an increase in market share and maximize the profits of the enterprise. Thus, there was an improved methodological framework for assessing the feasibility of using outsourcing in the enterprise. The confirmation is that the important aspects according to the "business process significance", "business process quality" and "cost ratio" that helped the institution to calculate a rationale index that is calculated for the purpose of conversion the business process to outsourcing, it is describes the managerial decision-making process as follows: strategic emphasis on basic operations, management approach to work, patterns of the business process development, among others for the modernization and growth of the institution, and increase their competitiveness in the market. Using the proposed methodology, it is possible to assess the importance of the business process for the enterprise and the company's own capabilities for its implementation, and based on the use of the outsourcing expediency matrix, determine the priority strategy for the selected business process. According to the results of the research, the process of executing outsourcing in enterprise's is a decision and delegating management, and therefore it is recommended to evaluate the importance of the business process for the enterprise's, and the enterprise's own capabilities to implement.

\section{Conclusion}

The analyzes and interpretations carried out in this study allowed reflections and inferences based on the identification of classification features of outsourcing, corresponding to certain stages of the appropriateness of outsourcing to perform a specific business process of the enterprise. When evaluating business processes, it is possible to make a decision - to concentrate our own resources on its improvement or to attract a third-party organization for the full or partial implementation of business processes. This will increase the efficiency of business processes, labor productivity, as well as create the prerequisites for the modernization and growth of the enterprise, increase competitiveness in the market, which will lead to an increase in market share and maximize the profits of the enterprise. Thus, there was an improved methodological framework for assessing the feasibility of using outsourcing in the enterprise. The study reflects on the implications of work organization to perform a specific business process of the enterprise. Its contribution is based, especially, on presenting results that are scarcely verified in national and international literature. In Iraq, despite the strong positioning for the use of outsourcing, little scientific contribution is made on the subject of the structure of the outsourcing mechanism of business operations in the experience of transferring. Generally, the results unveiled that using the proposed methodology, it is possible to assess the importance of the business process for the enterprise and the company's own capabilities for its implementation, and based on the use of the outsourcing expediency matrix, determine the priority strategy for the selected business process. At the same time, industrial companies should regulate commercial operations activities to the means of increasing their effectiveness through a comprehensive analysis of the effect of economic indicators on their development in the context of using an external source in this field. Lastly, the use of outsourcing leads to the organizational restructuring of the economic activity of the enterprise requires the creation of an appropriate mechanism and system for its provision, the development of a decision-making mechanism on the appropriateness of using outsourcing to increase the efficiency of operations and the competitiveness of industrial enterprises. Since the use of outsourcing is a comprehensive strategic decision, its adoption causes significant changes in the structure and results of the business, and therefore requires significant analytical training.

\section{Acknowledgement}

All authors contributed equally to the conception and design of the study.

\section{References}

Abdul, S. M. (2019). The importance of the role of data, accounting information and financial reports, In: MECSJ, 10. Available at: http://www.mecsj.com/ar 
Abdullah, Y., \& Aykut, B. (2014). Evaluation of the Effect of the Outsourcing on Resource Dependency and Transaction Cost Approach: A Research in Konya Oiz, Turkey. Procedia - Social and Behavioral Sciences, 10(9), 737-752.Available at: https://core.ac.uk/download/pdf/82532735.

Adesubomi, A. (2015). Organisational communication, the panacea for improved labour relations . Journal Studies in Business and Economics, 10(2), 5-16.

Al-Jajjawi, T. M., \& Al-Masoudi, H. A. (2004). Financial Accounting (Intermediate) according to the international standards for preparing financial reports, Dar Al-Kutub, Karbala, Iraq.

Alkarawy, H. G. (2018). Modern classification of outsourcing on enterprise. Bulletin of Chelyabinsk State University, 413(3), 111117.Available at: https://www.csu.ru/scientific-departments/vestnik/main.aspx.

Alkarawy, H. G. (2018). The mechanism of organization of outsourcing and assessment of its impact on the efficiency of an industrial enterprise. Journal of Economy and Entrepreneurship, 4(93), 985-993.

Alnoor, B., \& Leslie, W. (2014). Digitisation, 'Big Data' and the transformation of accounting information. Journal Accounting and Business Research, 44(4), 469-490.

Anokhin, A. (2010). Outsourcing: interstructural interaction organization. Economics and Business. 1, 182-189.Available at: https://cyberleninka.ru/article/n/autsorsing-organizatsiya-mezhstrukturnogo-vzaimodeystviya.

Bailal, M. A. (2018). The Importance of Internal Control in Accounting Outsourcing Companies to Increase the Confidence of Those Requesting Their Services in Iraq. Al-Rafidain Journal, 119(37), 59-80.

Christian, A. L., Diego A. L. \& Lucas, M. L. (2017). Comparative cost analysis between contracting and outsourcing logistics services: a case study in a company in the animal and plant health segment. Revista de Iniciação Cientifica da Libertas, 7(1), 57-75. Available at: http://riclibertas.libertas.edu.br.

Diego, A., Cleiton, E. R. \& Carlos, F. J. (2020). Manufacturing strategy method for outsourced footwear oriented to Agile Manufacturing. Innovar, 30(75), 99-118. Available at: https://doi.org/10.15446/innovar.v30n75.83260.

Furusawa, T., Ito K., Inui, T., \& Heiwai, T. (2015). Offshoring, Relationship-Specificity, and Domestic Production Networks. The Research Institute of Economy, Trade and Industry, 122(15), 3-25.Available at: https://pdfs.semsnticsholar.org.

Galina, N. (2019). Transformation of agricultural enterprises on the boundary of the XX-XXI centuries. IFAC-Papers-Online, 52(25), 225-230.Available at: https://doi.org/10.1016/i.ifacol.2019.12.477.

Havakhor, T., \& Sabherwal, R. (2019). Relationships between information technology and other investments: A contingent interaction model. Information Systems Research, 30(1). Available at: https://doi.org/10.1287/isre.2018.0803

Imad, A., \& Ala'a M. (2016). The effect of cost management on enhancing the efficiency of the supply chain. The Journal of Administration \& Economics, 10(6), 218-234.

Ioan, A., \& Vasile, D. (2010). Outsourcing the Business Services. Informatica Economică, 14(1),

Jordan, A. (2017). Project Management in Outsourcing. Thesis within International Business. Jönköping University. Available at: https://www.diva-portal.org.

José, C., \& Alberto, L., \& Ana M., (2016). Sourcing strategies and productivity: Evidence for Spanish manufacturing firms. BRQ Business Research Quarterly, 19(2), 90-106.

Jumana, M. (2014). The role of outsourcing in improving the performance of government institutions (case study: Syrian Telecom Company) Master Thesis, Tishreen University. Available at: http://mohe.gov.sy/master/Message/Mc/jomana\%20mahfoth.pdf

Katerina, K. (2017). Organizational and Economic Arrangements of Economic Systems Management. Revista ESPACIOS, 38(46). Available at: https:/www.revistaespacios.com.

Nataliya, V. K., Alkarawy, H. G., \& Vladimir I. Z. (2016). Outsourcing: The Improvement of Accounting System. Journal of Applied Economic Sciences, 4(42), 738-742.Available at: http://cesmaa.org/Extras/JAESA.

Nesma, S. M. (2018). Feasibility assessment of the decision to outsource the operation of accounting information systems in the Egyptian business environment. JSST, 19(3), 30-58..

Ruiz-Medrano, S. F. (2019). Implications of the figure of outsourcing in the labor rights and profits of companies in Mexico: a comparative analysis. Acta Universitaria 29, e1671.Available at: http://doi.org/10.15174.au.2019.1671.

Shadrack, T. (2017). Unionised Strikes Dynamics and Economic Performance: An Exploratory Study. Corporate Ownership \& Control, 14(3), 354-363.

Stojanov, M., (2017). The Challenges of offshoring and outsourcing. Trakia Journal of Sciences, 15(1), 87-92.

Sung, M., Gopesh A., Eric C., \& Joseph M. (2019). Resource co-specialization in outsourcing of enterprise systems software. Journal of Science and Technology Policy Management, 10 (5), 1015-1046.

Svetlana, M., \& Elina, G. (2015). Use of the chain of values for development outsourcing strategy. Procedia Economics and Finance, 24, 402-408.Available at: https://pdf.sciencedirectassets.com.

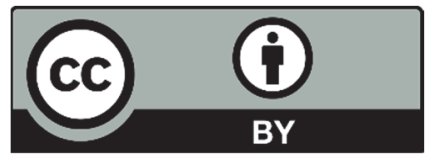

(C) 2021 by the authors; licensee Growing Science, Canada. This is an open access article distributed under the terms and conditions of the Creative Commons Attribution (CC-BY) license (http://creativecommons.org/licenses/by/4.0/). 